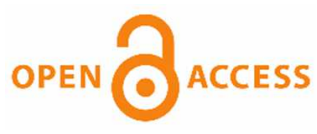

Authors' contribution:

A) conception and design of the study

B) acquisition of data

C) analysis and interpretation of data

D) manuscript preparation

E) obtaining funding

\title{
The Evaluation of Cohesion in the Sports Groups within a Romanian City
}

\author{
Oana Rusu
}

“Alexandru Ioan Cuza” University of Iaşi, Romania

ABSTRACT

We propose to conduct an analysis, by studying the influences exercised by certain variables (the biological gender, the ranking and the sociomotor space) on the level of cohesion among the sports teams in the municipality of Iaşi, Romania, evolving in the first leagues. A questionnaire was conducted on a number of 158 athletes (55 females, 103 males) who practice basketball, soccer, handball, rugby, volleyball. The responders answered the questionnaire regarding the group environment (GEQ). Factor analysis groups the items on two factors at the level of the Romanian subjects. The homogeneity of the instrument was evaluated for the entire scale, as well as independently for each of the two factors. The gender variable does not influence the level of social cohesion and the one of task cohesion among the sports teams taken into account. The ranking does not influence task cohesion among the teams studied. Both the ranking and the level of sociomotor space, as independent variables, determine significant differences regarding the level of social cohesion among the teams studied. The sociomotor space variable determines at the level of the teams sportive studied significant differences also regarding task cohesion.

KEYWORDS $\quad$ group cohesion, local sports teams, psychometric evaluation

\section{Introduction}

The identification in the scientific literature of several definitions highlights the diversity of the approach to cohesion, an important variable of the group dynamic.

Chang, Duck, and Bordia (2006) conducted a synthesis of delimitations for the concept of sports group cohesion: as the totality of forces contributing to the maintenance of the group as an entity (Festinger, Schachter, \& Back, 1950), as group resistance facing destructive forces (Gross \& Martin, 1952), but also as a "dynamic process that is reflected in the tendency for a group to stick together and remain united in the pursuit of its instrumental objectives and/or for the satisfaction of member affective needs" (Carron, 1982, p. 124). This leads to four characteristic of cohesion: multidimensionality (the existence of several variable factors from group to group), dynamism (variability of cohesion over time, favourable factors at a certain point may become critical in other development phases of group cohesion), instrumentality (any group is constituted based on of series of taskaccomplishing objectives) and affective aspect (the existence of social interactions between the group members facilitates the development of social cohesion).

McLeod and von Treuer (2013, p. 2) find definitions of recent researchers in terms of "stick-togetherness" of the group (Guzzo \& Dickson, 1996, Parrent \& Chin, 2008), "the desire of group members to stay together as a 
group" (Banki, 2010, p. 364), "how individual members of a team relate and work together as a unit" (Aoyagi et al., 2008, p. 30).

On the other hand, Salas et al. (2015) synthesize two approaches in the defining of cohesion: unidimensionality (the attraction of the members towards the group) and multidimensionality (the sum of forces determining the members to remain in the group).

Consequently, two types of forces are present: attraction towards the group (representing the social and group affiliation aspects) and maintaining of a control targeting the interests for task, performance and group productivity (Carron \& Hausenblas, 1998). Over time, groups may develop a different level of cohesion.

Systemic approach highlights three types of complex dynamics of the sports group that are led by interactions among the members and among groups in the contexts where they act. These dynamics are as follows: local, targeting the internal activities of the group; global, referring to the emergent properties of the group, emerged and developed from the local and contextual dynamics referring to the placement of the group in an action context modelling the group (Arrow et al., 2000). Within the global dynamics, along with other processes, cohesion is found as an emergent process emerging as result of social interactions between the group members, who coordinate their actions in order to preserve the group entity and to attain the objectives of the group and the affective needs. A recent study highlights this new perspective of approaching cohesion (McEwan and Beauchamp, 2014, cited in Eys \& Kim, 2017; Marks et al., 2001, cited in Salas et al., 2015).

Three types of cohesion were identified, the development of a group depending on both the internal dynamic of the group and the relationships with other groups: normative and cultural cohesion - referring to the common attitudes of the group members, to rituals, to the community standards and values, functional cohesion referring to group functioning and related to the organisation system, to the communication networks, to the status and roles networks, to the nature of the task, to the degree of adjustment of resources in relation with the activities conducted and the socio-affective cohesion - corresponds to the affinities between the group members (Parlebas, 1976).

The researchers' interest for the study of this phenomenon derives from the consequences on the group and the group development in the context where they act:

- cohesion may influence the satisfaction of the group members - in a cohesive group, individuals have high morale, high self-esteem, share feelings of security, high level of participation to the group life, etc (Widmeyer \& Williams, 1991; Andrews et al., 2008, Marcos et al., 2010; Taghizadeh \& Shojaie, 2012; Paradis \& Loughead, 2012; Carless and De Paola, 2000, cited in McLeod \& von Treuer, 2013; Onag \& Tepeci, 2014; Spink et al., 2005, Wolf et al., 2015, cited in Eys \& Kim, 2017; Haddera, 2016; Filho, 2019);

- cohesion may have consequences on performance - positive and negative effects on group performance are reported (Brawley, 1990; Evans \& Dion, 1991; Gully, Devine, \& Whitney, 1995; Abric, 1996; Chang and Bordia, 2001; Gammage et al., 2001; Carron et al., 2002b and 2002c; Shapcott et al., 2006; Chang et al., 2006; Sopa \& Pomohaci, 2014; Beal et al., 2003, Mullen \& Cooper, 1994, cited in Salas et al., 2015; Eys et al., 2015; Muthiane et al., 2015; Smith, 2015; Carron, 2005, Rovio et al, 2009, Shapcott \& Carron, 2010, Bruner et al., 2014, cited in Eys \& Kim, 2017).

- cohesion exercises influences, often negative ones, on group thinking (Janis, 1972; Oberlé, 1995)

The new theoretical approaches - in contradiction with the classic models studying the phenomenon of cohesion, discussing cohesion as a result of the interdependence of the individuals with a role in maintaining the wish to remain together - propose to discuss this phenomenon from the perspectives of social identity and self-categorisation theories (Hogg, 1995; Bruner et al., 2014, cited by Eys \& Kim, 2017). Group behaviours may also be explained as individual, cognitive traits. In this respect, the social identity of an individual is built by his self-perception as a group member. 
External factors (the reward and compensation systems, the threats and challenges to which the group members are exposed) and internal factors (related to the size of the group, the age of the team members, to the similarities between athletes, to internal organisation and leadership, to the motivation of the athletes, to sports tradition, etc) of the group can determine different degrees of cohesion between the members of a group (Mudrak, 1989; Fischer, 1990; Widmeyer, Brawley, \& Carron, 1990; Valleran, 1994; Oberlé, 1995; Patterson, Carron, \& Loughead, 2005; Hoigaard, Safvenbom, \& Tonnessen, 2006; Gomes, Pereira, \& Pinheiro, 2008; Vincer \& Loughead, 2010; Bosselut at al., 2012).

Carron $(1982,1988)$ identified a "conceptual system" within which he identified four categories of factors that influence the development of cohesion within the sports groups:

a) the environmental factors (e.g., the group size - Carron, 1988);

b) the personal factors (e.g., the similarity of the group members - Eitzen, 1973; the satisfaction of the group members concerning the social and task aspects of the group - Martens and Peterson, 1971);

c) the leadership factors (the clarity of group goals and member roles - Raven and Reitsema 1957, the acknowledgement of contributions made by the members - Biondo and Piritano 1985, ensuring the implication of the group members in the decision-making process - Carron and Chelladurai, 1981);

d) the factors related to the team (the successes/performances previously attained - Bakeman \& Helmreich, 1975; Carron \& Ball, 1977; Williams \& Hacker, 1982; Shangi \& Carron, 1987; the communication between the group members (Carron, 1988), variables of the group's goal, as well as the acknowledgement of the importance of the group's goal (Hollenbeck \& Williams, 1987) and the participation in formulating the group's goal.

The development of group cohesion is a social modelling process, requiring time and effort, all the more in the sports activity. The level of the group's efficiency and performance can be determined by the positive or negative influence of certain factors (the homogeneity/heterogeneity of the group, the agreement/disagreement on the goals and objectives of the group, the individual attraction to the group, the quality and frequency of the interactions between the group members, the clear distribution of the tasks and roles within the group, the presence/absence of threats outside the group, the leadership type, etc). Besides these favourable/unfavourable factors of cohesion, the character of the athletes, the motivation and the level of multifactor training, communication relationships between athletes and between athletes and coaches, emulation between the group members can be considered specific factors.

Both the coaches and the managers of the sports groups have as objective the formation and development of a cohesive team, being known that the adjustment of individual intentions and trends to the common goal, the mutual support in actions, the cooperation and communication between players, the collaboration in the application of the game system (the tactical schemes), etc, represent factors favouring the efficiency and performance of the group.

Some researchers have highlighted the relation between group cohesion and the way success or failure is experienced (Spink, 1992). Most of the times, the tension caused by the pressure of competition consolidates cohesion. In certain situations, success or failure may have negative consequences on the level of cohesion, on decreasing the "morale" of the team. In the sports groups, where there is strong motivation for attaining performance, success or failure increases the level of cohesion; if the group acts based on affiliation motivation, the consequences are contradictory, as the failure influences group cohesion negatively.

The study the issue of the spatial distribution of the sports group members focuses on highlighting the social factors regulating the intragroup relationships. The sports group members learn to communicate with the others in the conditions of the motor activity (through movement) (sociomotor learning). The communication relationships, the organisation possibilities of the athletes in the presence of the opponent are different due to the contact distance in relation with the opponent. 
Parlebas (1974) defines the sociomotor space as "the distance of contact between athletes (in relation with the opponent) and the space (surface) available to each of them for the technical and tactical evolution". The surface of individual space is directly proportional with the distance of contact and reversely proportional with sports artistry. The smaller the individual action space, the smaller the distance of contact; consequently, the level of individual "artistry" increases. These spaces are different from one sport to another, thus involving the unfolding of identical motor actions but in different combinations.

From the perspective of the level of sociomotor conducts of each group member, but also of the group overall, the spatial distribution of the members of a sports team is done by the field distribution (the game system in the sports games) or by the synchronous working formations (in the sports with team competitions - gymnastics, swimming, ice skating, water jumps, etc).

\section{Methods}

Our purpose is to conduct an analysis, by studying the influences of certain variables (the biological gender, the ranking and the sociomotor space) on the level of cohesion among the sports teams in the municipality of Iaşi, Romania. We also aimed at pointing out the (positive and/or negative) sense of these influences.

Two general hypotheses were formulated, each comprising 6 specific hypotheses.

1. There are interaction effects of the variables biological gender, ranking and sociomotor space on cohesion (social and per task) at the level of the sports teams studied.

1.1. There is an interaction effect of the variables biological gender and ranking on social cohesion.

1.2. There is an interaction effect of the variables biological gender and sociomotor space on social cohesion.

1.3. There is an interaction effect of the variables ranking and sociomotor space on social cohesion.

1.4. There is an interaction effect of the variables biological gender and ranking on task cohesion.

1.5. There is an interaction effect of the variables biological gender and sociomotor space on task cohesion.

1.6. There is an interaction effect of the variables ranking and sociomotor space on task cohesion.

2. There are significant statistical differences at the level of cohesion (social and/or per task) at the level of the sports teams studied, by the three variables: biological gender, ranking, sociomotor space.

2.1. The level of task cohesion, within the sports teams in the municipality of Iaşi, is significantly higher among the teams within the first league compared to the teams of the second league.

2.2. The level of social cohesion, within the sports teams studied, is significantly higher among the teams of the second league compared to the teams of the first leagues.

2.3. The level of task cohesion, within the sports teams included in the study hereof, is significantly higher among the teams with a small sociomotor space compared to the teams with a large sociomotor space.

2.4. The level of social cohesion, within the sports teams in the municipality of Iaşi, is significantly higher among the teams with a small sociomotor space compared to the teams with a large sociomotor space.

2.5. The women's sports teams are more socially cohesive than the men's sports teams.

2.6. The men's sports teams obtain higher values in task cohesion compared to the women's sports teams.

\section{Participants}

Though this is the second largest city in Romania, there are a small number of local sports teams. The research sample comprises all the athletes activating among the sports teams in the municipality of Iasi $(n=158$ subjects, 55 females, 103 males), aged between 18 and 43, with an experience of at least 4 years of sports practice and with attendance to at least 4 team practices. They conduct their competitive activity in the highest levels in the national championships: basketball (women's -15 , the first league and men's -15 , the second league), soccer (men's -25 the first league and 25 in the second league), handball (men's - 15 the second league), rugby 
(women's -16 , the first league and men's -23 , the first league), volleyball (women's -16 , the first league and 12, the second league) (see Figure 1).

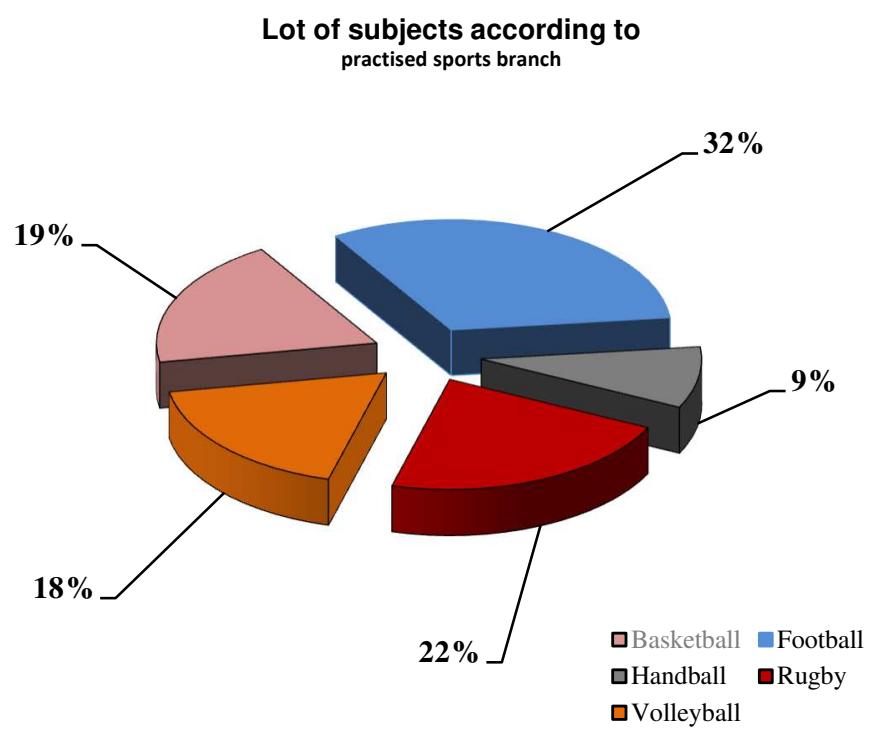

Figure 1. Research sample according to practiced sports branch Source: own study.

\section{Procedure}

The questionnaire was applied within the training program (right after the practice, in the locker rooms), towards the end of the competitive period. Beforehand, the coaches and the management of clubs were asked for their consent, while the subjects were required to fill in the questionnaire in a personal manner and they were assured that their answers would remain confidential.

\section{Instrument}

Cohesion was evaluated using the questionnaire regarding the group environment (GEQ) developed by Carron et al., 1985, probably the most commonly used instrument in measuring cohesion. It was translated and adapted into Romanian by Rusu (2009). The instrument, derived from a conceptual model of cohesion, comprises 18 items scored on a Likert scale from 1 (strongly disagree) to 9 (strongly agree). The questionnaire measures four dimensions of cohesion:

1. GI-T (Group Integration-Task) - items 10, 12, 14, 16, 18;

2. GI-S (Group Integration-Social) - items 11, 13, 15, 17;

3. ATG-T (Individual Attractions to the Group-Task) - items 2, 4, 6, 8;

4. ATG-S (Individual Attractions to the Group) - items 1, 3, 5, 7, 9.

The ATG-T and GI-S factors include 4 items each, while ATG-S and GI-T 5 items each. The scores for each subscale can be obtained by calculating the sum of the items corresponding to the scales. The scores to some items $(1,2,3,4,6,7,8,11,13,14,17,18)$ are reversed.

The internal consistency of the GEQ was highlighted within several researches conducted: Carron et al., 1985, Widmeyer et al., 1985 (cited by Carron et al., 2002a), Carron et al. 2002a, Ntoumanis \& Anggelonidis, 2004, Li \& Harmer, 1996; Hu \& Bentler, 1999; Schutz et al., 1994; Sullivan, 2002 (cited by Ntoumanis \& Anggelonidis, 2004). In addition, recent studies have used adapted versions of the GEQ, analysing only two 
dimensions compared to four of the cohesion, namely social and task (Eys et al., 2009, Martin et al., 2012, cited by Eys \& Kim, 2017).

\section{Research variables}

Independent variables: the biological gender of the subjects (men and women), the performance level (second level - the teams play in the championships within the first league - with different names depending on the sports branch: Division A, National Division; second level - the teams conducting their competitive activity in championships under various names: Division A, Division B, Division C) (see Table 1), the sociomotor space (we have considered a small sociomotor space in sports such as volleyball, handball and basketball, while a large sociomotor space in sports such as soccer, rugby) (see Table 2).

Table 1. Independent variable performance level

\begin{tabular}{ll}
\hline Level of performance & Sports teams \\
\hline Performance level I & Football, male \\
& Rugby, male \\
& Volleyball, female \\
& Bascketball, female \\
& Rugby, female \\
Performance level II & Handball, male \\
& Bascketball \\
& Volleyball, female \\
& Football, male, male \\
\hline
\end{tabular}

Source: own study.

Table 2. Independent variable sociomotric space

\begin{tabular}{lll}
\hline Sociomotric space & Sports & Surface $\left(\right.$ in $\left.\mathrm{m}^{2}\right)$ \\
\hline Small sociomotric space & Volleyball & 13.5 \\
& Basketball & 42 \\
& Handball & 57.14 \\
Large sociomotric space & Rugby, male & 233.33 \\
& Football & 324.54 \\
& Rubgy, female & 1000 \\
\hline
\end{tabular}

Source: own study.

Dependent variables: task cohesion, social cohesion.

The variable task cohesion reunites 2 subscales in the original GI-T questionnaire (Group Integration-Task) and ATG-T (Individual Attractions to the Group-Task), while the variable social cohesion encompasses the subscales GI-S (Group Integration-Social) and ATG-S (Individual Attractions to the Group-Social) within the original questionnaire.

\section{Method}

The results were processed using SPSS, factor analysis, ANOVA bifactor variance analysis and the $t$ tests of significance between the means for independent samples.

\section{Results}

Within our research, the questionnaire GEQ was translated and pretested on a sample of athletes $(\mathrm{N}=30,12$ females, 18 males), members of women's teams - basketball and volleyball - and men's teams - handball, 
basketball and soccer - activating in Iaşi, Romania, in the national championships, in the first league. Also fluent in English, the subjects were given the questionnaire in Romanian, and after a week the English version.

As a result of the factor analysis on main elements, with Varimax rotation, we highlighted the grouping of the items on two factors explaining $66.90 \%$ of the total variance of the results (Factor $1-31.16 \%$; Factor 2 $60.25 \%$ for eigenvalue estimates). The sphericity condition was met, thus obtaining a value of the KMO index $=0.806, \mathrm{p}=0.000$.

A possible explanation for grouping the items on two factors, unlike the four ones identified in the original instrument, could be provided by the cultural specifics where the members of the groups studied act. On the other hand, the subjects included in the study may have been more interested in what is called task cohesion and social cohesion and less in what concerns the perceptions related to attraction to the group and group integration.

Factor 1 was called task cohesion, thus encompassing items 2, 4, 6, 8, 10, 12, 14, 16, 18 (in fact, the items included in the dimensions ATG-T and GI-T within the original questionnaire). Factor 2, social cohesion, comprises items 1, 3, 5, 7, 9, 11, 13, 15, 17 (the items included in the dimensions ATG-S and GI-S within the original instrument).

In order to assess the reliability of the Romanian version of the GEQ instrument, Alpha Cronbach's reliability coefficient. The values of Alpha Cronbach's index obtained for the entire scale has a high value, $\alpha=.88$.

The homogeneity of the instrument was evaluated independently on the two factors, thus obtaining the following results: for the scale of task cohesion $\alpha=.91$, while for the scale of social cohesion $\alpha=.91$.

The concurrent validity coefficient GEQ was calculated in relation with the total scores for the two scales of GEQ, in the English and in the Romanian versions. The concurrent validity coefficient of the task cohesion scale is 0.548 (see Table 3), while for social cohesion is 0.528 (see Table 4). Both values are positive and significant, they are lower than expected.

Table 3. Concurrent validity coefficient of task cohesion

\begin{tabular}{llrr}
\hline & & CSARROM & CSARENG \\
\hline CSARROM & Pearson Correlation & 1,000 &, $548^{* *}$ \\
& Sig. (2-tailed) & 30 &, 002 \\
& $\mathrm{~N}$ &, $548^{* *}$ & 30 \\
CSARENG & Pearson Correlation &, 002 & 1,000 \\
& Sig. (2-tailed) & 30 & 30 \\
& $\mathrm{~N}$ & \\
\hline
\end{tabular}

** Correlation is significant at the 0.01 level (2-tailed).

Source: own study.

Table 4. Concurrent validity coefficient of social cohesion

\begin{tabular}{llrr}
\hline & & CSOCROM & CSOCENG \\
\hline CSOCROM & Pearson Correlation & 1,000 &, $528^{* *}$ \\
& Sig. (2-tailed) &, &, 002 \\
& $\mathrm{~N}$ & 30 & 30 \\
CSOCENG & Pearson Correlation &, $528^{* *}$ & 1,000 \\
& Sig. (2-tailed) &, 002 & 30 \\
& $\mathrm{~N}$ & 30 & 30 \\
\hline
\end{tabular}

** Correlation is significant at the 0.01 level (2-tailed).

Source: own study. 


\section{Analysis and interpretation of results}

In order to investigate the influence of the biological gender, of the ranking and of the sociomotor space on the level of social and task cohesion, we have analysed initially the degree of meeting the KMO sphericity $=0.880$, $\mathrm{p}=0.000$.

In the same manner as in the pretesting phase, the analysis on main elements with an octogonal rotation highlighted the grouping of items on two factors, explaining $60.117 \%$ of the total variance of the results (factor 1 - task cohesion $-34.241 \%$, factor 2 - social cohesion $-25.877 \%$ - for eigenvalue estimates).

Factor 1, called task cohesion, includes items 2, 4, 6, 8, 10, 12, 14, 16, 18 (in fact, the items included in the dimensions ATG-T and GI-T within the original questionnaire). Factor 2, social cohesion, comprises items 1, 3, 5, 7, 9, 11, 13, 15, 17 (items included in the dimensions ATG-S and GI-S within the original instrument).

The homogeneity of the instrument was evaluated for the entire scale, as well as independently on the two factors, thus obtaining the following results: for the entire scale $\alpha=.88$, for the scale of task cohesion $\alpha=.87$, while for the scale of social cohesion $\alpha=.94$.

The bifactor variance analysis demonstrates a significant effect, on social cohesion, in case of the ranking $[\mathrm{F}(1.154)=7.39, \mathrm{p}=0.007<0.05]$, but not also in case of the variable biological gender $[\mathrm{F}(1.154)=0.36, \mathrm{p}=0.54$ $>0.05]$ or in case of the interaction between the two variables $[\mathrm{F}(1.154)=0.12, \mathrm{p}=0.72>0.05]$.

A significant effect was obtained in case of the variable sociomotor space $[\mathrm{F}(1.154)=7.08, \mathrm{p}=0.009<0.05]$. The rest of the effects are insignificant: for the gender variable $-[\mathrm{F}(1.154)=1.80, \mathrm{p}=0.18>0.05]$, while for the interaction effect gender*sociomotor space $-[F(1.154)=3.05, \mathrm{p}=0.08>0.05]$. The sociomotor space influences social cohesion among the teams studied regardless of the biological gender of the subjects.

The bifactor variance analysis shows significant effects, on social cohesion, both in case of the ranking $[\mathrm{F}(1.154)$ $=5.91, \mathrm{p}=0.01]$, and of the sociomotor space $[\mathrm{F}(1.154)=6.11, \mathrm{p}=0.01]$. There are no significant effect in case of the interaction between the two variables $[\mathrm{F}(1.154)=2.09, \mathrm{p}=0.15>0.05]$.

Both the main effect of the variable biological gender on task cohesion $[\mathrm{F}(1.154)=2.47, \mathrm{p}=0.11>0.05]$, and the one of the variable ranking $[\mathrm{F}(1.154)=0.49, \mathrm{p}=0.48>0.05]$ are statistically insignificant. In addition, the interaction effect between the variables biological gender and ranking is statistically insignificant $[\mathrm{F}(1.154)=$ $0.13, \mathrm{p}=0.71>0.05]$.

The sociomotor space influences task cohesion among the teams studied $[\mathrm{F}(1.154)=6.06, \mathrm{p}=0.01]$ regardless of the biological gender of the subjects $[\mathrm{F}(1.154)=0.001, \mathrm{p}=0.97>0.05]$. The interaction effect between the two variables is statistically insignificant $[\mathrm{F}(1.154)=1.03, \mathrm{p}=0.31>0.05]$.

The bifactor variance analysis demonstrates a significant effect on task cohesion in case of the sociomotor space $[\mathrm{F}(1.154)=7.26, \mathrm{p}=0.008<0.05]$. The rest of the effects are insignificant: for the variable ranking $[\mathrm{F}(1.154)=$ $0.41, p=0.52>0.05]$; the interaction between the two variables $[F(1.154)=0.01, p=0.9>0.05]$.

The application of the $t$ tests for independent samples has highlighted the differences at the level of social cohesion and task cohesion, between the groups studied by the independent variables ranking, sociomotor space and biological gender.

The level of task cohesion among the teams evolving in the first league (Division A - basketball women's, Division A1 - volleyball women's, League I - soccer men's, National Division - rugby men's, Division A rugby women's) is not different from the level of task cohesion of the teams evolving in the second league (Division B - basketball men's, Division A - handball men's, volleyball women's - the second team, Division $\mathrm{C}$ - soccer men's). The difference is not statistically significant $[\mathrm{t}(156)=0.135, \mathrm{p}=0.89>0.05]$, the results obtained being illustrated in the Table below. Hypothesis nu se confirmă.

The sports teams evolving in the second leagues (Division B - basketball men's, Division A - handball men's, volleyball women's - the second team, Division C - soccer men's) are more socially cohesive than the sports 
teams evolving in the first leagues (Division A -basketball women's, League I - soccer men's, National Division - rugby men's, Division A1 - volleyball women's, Division A - rugby women's). The difference obtained is statistically significant: $[\mathrm{t}(156)=-3.172, \mathrm{p}=0.002<0.05]$. The results, featured in the Table below, also show the means of scores obtained by the sports teams in Iaşi. Consequently, the hypothesis formulated is confirmed.

The sports teams where the sociomotor space of the athletes is small are more cohesive, from the perspective of accomplishing the game tasks (task cohesion), compared to the sports teams where the sociomotor space for each athlete is large. The difference obtained is statistically significant, the results obtained $[t(156)=2.676, p$ $=0.008<0.05]$, also featured in the Table below, thus confirming the hypothesis.

The sports teams where players benefit from a small sociomotor space are more cohesive, from the social perspective, compared to the sports teams where the players have a large sociomotor space. The differences, illustrated by the results obtained, $[\mathrm{t}(156)=3.064, \mathrm{p}=0.003<0.05]$, are statistically significant. The hypothesis is confirmed.

The results obtained show that there are no significant differences from the statistical perspective between the women's and men's sports teams regarding the level of social cohesion; $[t(156)=0.188, p=0.85>0.05]$. The hypothesis was not confirmed.

There are no significant differences at the level of task cohesion between the women's and men's sports teams. The data obtained show that $[\mathrm{t}(156)=-1.446, \mathrm{p}=0.15>0.05]$ and consequently, the aforementioned hypothesis was not confirmed.

\section{Discussion and conclusions}

Our investigative approach has involved the study of certain variables that influence the level of cohesion within of a sports team (in terms of both social cohesion and task cohesion). The independent variables taken into consideration in the context of the research (the biological gender, the ranking league of the sports practiced and the sociomotor space of action corresponding to the athletes of a team) can be considered the basis of certain explanations concerning the variability in the level of social cohesion and task cohesion within the sports teams studied.

It may be appraised that, based on the data obtained in the analyses conducted, that the hypotheses formulated were partially confirmed. The results of our study allow us to issue a series of conclusions.

The gender variable does not influence the level of social cohesion and the one of task cohesion among the sports teams taken into account.

Both the ranking and the sociomotor space, as independent variables, determine significant differences regarding the level of social cohesion among the teams studied.

Upon analysing the results obtained, the sports teams studied activating in the second league are more socially cohesive, a possible cause thereof being the lower threats to which they are exposed compared to the teams of the first leagues. We refer here to the risk of slipping back to a second league from the first league. Both the men's basketball and the men's handball teams have ranked at the end of the championship in the upper half, unlike the teams of the first leagues that ranked at the end of the previous competitive year in the lower half (the women's basketball and soccer teams, thus fighting to avoid slipping back).

The sports teams where the sociomotor space of each player for the technical and tactical evolution is small (volleyball, basketball, handball), are more socially cohesive than those with a large sociomotor space (rugby and soccer). A small sociomotor space determines an increase in "functional distance" (which comprises the interactions between the group members), leading to more numerous communication relationships between the 
team members, and thus to a development of interpersonal relationships. This is reflected by a high level of social cohesion among the sports teams in question.

A variable sociomotor space determines at the level of the sports teams studied significant differences regarding task cohesion, too. The spatial relationships between team members are determined within sports games by tactical intentionality. The way game tasks are reflected in the conscience of the athletes, and their attitude is different by the way they apply the tactical game strategies ("man-to-man" or "zone" defence). The offensive tactics impose a clearer game perception, as well the use of creating capacity to overcome the opponent's opposition. Consequently, the smaller the space, the higher an athlete's artistry. All of the above determine higher task cohesion among the teams studied, where the sociomotor space of each player for the technical and tactical evolution is small.

The results obtained show that the ranking does not influence task cohesion among the teams studied.

The study of group cohesion, of its dimensions (social cohesion and task cohesion) is relevant in the analysis concerning the satisfaction of the members and the group performance, followed in the sports activity. The values obtained confirm the information reported by other researchers in the previous studies.

The results of the study hereof can be influenced by a series of limits. Given the conclusive character of the study and the existence of a limited number of teams at the level of the municipality of Iaşi, Romania, the research included a relatively small number of subjects, without any balance in terms of the variable biological gender. The absence or lack of interest for the subjects' perceptions regarding attraction to the group and group integration made it possible to analyse only two of the four dimensions of the original instrument used for measuring cohesion. In addition, the inclusion in the study of several sports, (interaction sports, team sports and co-action sports, individual sports with team events) would provide the possibility for a more thorough analysis. The measurement of cohesion at the level of the teams studied at the end of the competitive season enabled the interpretation of the results taking into account this moment. A longitudinal study, where the measurement of the level of cohesion would concern several moments, can be useful, as it can bring additional information to be used by both athletes and coaches in order to minimise the negative aspects and to make the teams more effective, (to obtain better performances and to get higher satisfaction).

Future studies may extend the study concerning cohesion within the sports teams, on various levels of performance, at regional or national level. The inclusion in the study of several sports (interaction sports - team and co-action sports - individual sports with team events) and of other independent variables (e.g., leadership) would provide the possibility of a more detailed analysis. In addition, it would be effective to conduct more detailed investigative approaches concerning the evolution of the cohesion level along a competitive season, as well as the correlation between cohesion and personal variables (the satisfaction of the members) and group variables (group performance).

\section{REFERENCES}

Abric, J.C. (1996). Psychologie de la communications: méthodes et théories, Paris: Dimand Colin.

Arrow, H., McGrath, J.E., Berdahl, J.L. (2000). Small Groups as a Complex Systems: Formation, Coordination, Development, an Adaptation. Sage Publications

Bakeman, R., \& Helmreich, R. (1975).Cohesiveness and Performance: Covariation and Causality in an Undersea Environment. Journal of Experimental Social Psychology, 11, 478-489. http://dx.doi.org/10.1016/0022-1031(75)90050-5

Biondo, R., \& Pirritano, M. (1985). The Effects of Sport Practice upon the Psycho-social Integration of the Team. International Journal of Sport Psychology, 16, 28-36.

Bosselut, G., McLaren, C.D., Eys, M.A., \& Henze, J.P. (2012). Reciprocity of the Relationship between Role Ambiguity and Group Cohesion in Youth Interdependent Sport. Psychology of Sport and Exercise, 13, 341-348. doi: 10.1016/j.psychsport.2004.04.004 
Brawley, L.R. (1990). Group Cohesion - Status, Problems, and Future Directions. International Journal of Sport Psychology, 21, 355-379.

Carron, A.V., \& Ball, J.R. (1977). Cause-Effect Characteristics of Cohesiveness and Participation Motivation in Intercollegiate Hockey. International Review of Sport Sociology, 12, 49-60. doi: 10.1177/101269027701200203

Carron, A.V., \& Chelladurai P. (1981). The Dynamics of Group Cohesiveness in Sport. Journal of Sport Psychology, 3, 123-139.

Carron, A.V. (1982). Cohesiveness in Sport Groups: Interpretations and Considerations. Journal of Sport Psychology, 4 , 123-138.

Carron, A.V., Widmeyer, W.N., \& Brawley, L.R. (1985). The Development of an Instrument to Assess Cohesion in Sport Teams: The group Environment Questionnaire. Journal of Sport Psychology, 7, 244-266.

Carron, A.V. (1988). Group Dynamics in Sport. London, Ontario:Spodym.

Carron, A.V, \& Hausenblas, H.A. (1998). Group Dynamics in Sport, second edition. USA: Book Crafters.

Carron, A.V., Brawley, L.R., \& Widmeyer, W.N. (2002a). The Group Environment Questionnaire Test Manual. Morgantown, WV: Fitness Information Technology.

Carron, A.V., Bray, S.R., \& Eys, M.A. (2002b). Team cohesion and team success in sport. Journal of Sports Sciences, 20:2, 119-126, Taylor \& Francis Online. https://doi.org/10.1080/026404102317200828

Carron, A.V., Colman, M.M., Wheeler, J., and Stevens, D. (2002c). Cohesion and Performance in Sport: A Meta Analysis. Journal of Sport \& Exercise Psychology, 24,168-188. Human Kinetics Publishers, In

Chang, A., \& Bordia, P. (2001). A Multidimensional Approach to the Group Cohesion-Group Performance Relationship. Small Group Research, 32, 379-405, Sage Publication. doi: 10.1177/104649640103200401

Chang, A., Duck, J., \& Bordia, P. (2006). Understanting the Multidimensionality of Group Development. Small Group Research, 37, 327-350. Sage Publications. doi: 10.1177/1046496406290564

Eitzen, S. (1973). The Effect of Group Structure on the Success of Athletic Teams. International Review of Sport Sociology, 8, 7-17. PUB ID: 103-335-107.

Evans, C.R., \& Dion, K.L. (1991). Group Cohesion and Performance. A Meta-Analysis. Small Group Research, 22, 175186, Sage Publication. doi: 10.1177/1046496491222002

Eys, S.M., and Kim, J. (2017). Team Building and Group Cohesion in the Context of Sport and Performance Psychology. Organizational and Institutional Psychology, Sports Psychology . 1-21. doi: 10.1093/acrefore/9780190236557.013.186

Festinger, L., Schachter, S., \& Back, K. (1950). Social Pressure in Informal Groups. New York: Harper and Row.

Filho, E. (2019). Team Dynamics Theory: Nomological network among cohesion, team mental models, coordination, and collective efficacy. Sport Sciences for Health, 15, 1-20. Doi: https://doi.org/10.1007/s11332-018-0519-1

Fischer, G.N. (1990). Le champ du social, Paris: Dunod.

Gammage, K.L., Carron, A.V., \& Estabrooks, P.A. (2001). Team Cohesion and Individiual Productivity. The Influence of the Norm for Productivity and the Identificability of Individual Effort. Small Group Research, 32, 3-18, Sage Publication. doi: 10.1177/104649640103200101

Gomes, A.R., Pereira, A.P., \& Pinheiro, A.R. (2008). Leadership, Cohesion and Satisfaction in Sporting Teams: A Study with Portuguese Football and Futsal Athletes. Psicologia-Reflexao E Critica, 21, 482-491.

Gross, N., \& Martin, W. (1952). On Group Cohesiveness. American Journal of Sociology, 57, 546-566.

Gully, S.M., Devine, D.J., \&Whitney, D. (1995). A Meta-analysis of Cohesion and Performance. Effects of Level of Analysis and Task Interdependence. Small Group Research, 26, 479-520, Sage Publication. doi: $10.1177 / 1046496495264003$

Haddera, T.A. (2016). Investigating the Relationship between Team Cohesion and Self-Presentation among Different Competitive Team Sports of Ethiopian Universities. Momona Ethiopian Journal of Science (MEJS), V8(1):62-74. doi: http://dx.doi.org/10.4314/mejs.v8i1.

Hoigaard, R., Safvenbom, R., \& Tonnessen, F.E. (2006). The Relationship between Group Cohesion, Group Norms and Perceived Social Loafing in Soccer Teams. Small Groups Research, 22, 217-232. doi: 10.1177/1046496406287311

Hogg, M.A. (1995). Le concept de cohésion reformulé: une approche en termes de catégorisation et identité sociale. In Mugny, G., Oberlé, D., \& Beauvois, J.L. La psychologie sociale, vol.I: Relations humaines, groupes et influence sociale, Grenoble: PUG.

Hollenbeck, J.R., and Williams C.R. (1987). Goal Importance, Self-focus, and the Goal-setting Process. Journal of Applied Psychology, 72, 204-211. doi: 10.1037/0021-9010.72.2.204 
Iturbide, L.M., Elosua, P., and Yanes, F. (2010). A Measure of Team Cohesion in Sport. Spanish Adaptation of Group Environment Questionnaire (GEQ). Psicothema, 22, 482-488.

Janis, I.L. (1972). Victims of Groupthink, Boston: Houghton Rifflin Co.

Marcos, F.M.L., Miguel, P.A.S., Oliva, D.S., and Calvo,T.G. (2010). Interactive Effects of Team Cohesion on Perceived Efficacy in Semi-professional Sport. Journal of Sports Science and Medicine, 9, 320-325

Martens, R., and Peterson, J. (1971).Group Cohesiveness as a Determinant of Success and Member Satisfaction in Team Performance. International Review of Sport Psychology, 6, 49-71.

McLeod, J., and von Treuer, K. (2013). Towards a Cohesive Theory of Cohesion. International Journal of Business and Social Research (IJBSR), 3:12, 1-11. http://dx.doi.org/10.18533/ijbsr.v3i12.338

Mudrak, P.E. (1989). Defining Group Cohesion. A legacy of confusion? Small Group Research. 20, 32-49, Sage Publication. doi: 10.1177/104649648902000103

Muthiane, C.M., Rintaugu, E.G., and Mwisukha, A. (2015). The Relationship between Team Cohesion and Performance in Basketball League in Kenya. International Journal of Applied Psychology, 5(4): 90-95. doi: 10.5923/j.ijap.20150504.02

Ntoumanis N., \& Aggelonidis, Y. (2004). A Psychometric Evaluation of the Group Environment Questionnaire in a Sample of Elite and Regional Level Greek Volleyball Players. European Physical Education Review, 10, 261-278, Sage Publications. doi: 10.1177/1356336X04047126

Oberlé, D. (1995). Cohésion et rôles dans les groupes. In Mugny, G., Oberlé, D., \& Beauvois, J.L.. La psychologie sociale, Grenoble: PUG.

Onag, Z., \& Tepeci, M. (2014). Team Effectiveness in Sport Teams: the Effects of Team Cohesion Intra Team Communication and Team Norms on Team Member Satisfaction and Intent to Remain, Procedia - Social and Behavioral Sciences, 150, 420-428, Elsevier. http://creativecommons.org/licenses/by-nc-nd/3.0/

Paradis, K.F., \& Loughead, T.M. (2012). Examining the Mediating Role of Cohesion between Athelte Leadership and Athlete Satisfaction in Youth Sport. International Journal of Sport Psychology, 43, 117-136

Parlebas, P. (1974). Sociomotric space, translation in Sport for Children and Youths, no. XXIII, 1975, 3-21 (in Romanian). Parlebas, P. (1976). Activités physiques et éducation motrice, Paris: EPS.

Patterson, M.M., Carron, A.V., \& Loughead, T.M. (2005). The Influence of Team Norms on the Cohesion-Self-Reported Performance Relationship: A Multi-Level Analysis. Psychology of Sport and Exercise, 6, $479-493$. doi:10.1016/j.psychsport.2004.04.004

Raven, B.H., \& Reitsema, J. (1957). The Effects of Varied Clarity of Group Goal and Group Path upon the Individual and his Relation to the Group. Human Relations, 10, 29-48.doi: 10.1177/001872675701000102

Rusu, O. (2009). Psycho-social Dimensions of Small Groups in Local Community. Case study - Sports Teams, unpublished doctoral thesis, „Al.I.Cuza” University of Iaşi, Romania.

Salas, E., Grossman, R., Hughes, A.M., Coultas, C.W. (2015). Measuring Team Cohesion: Observations from the Science. Human Factors, 57:3, 365-374. doi: 10.1177/0018720815578267

Shangi, G., \& Carron, A.V. (1987). Group Cohesion and its Relationship with Performance and Satisfaction among High School Basketball Players. Canadian Journal of Sport Sciences, 12, 20.

Shapcott, K.M., Carron, A.V., Burke, S.M., Bradshaw, M.H., \& Estabrooks, P.A. (2006). Member Diversity and Cohesion and Performance in Walking Groups. Small Group Research, 37, 701-720, Sage Publication. doi: $10.1177 / 1046496406294545$

Smith, J.K. (2015). How to Achieve Team Cohesion through Competition in Sport: An Organizational Model. The Sport Journal. DOI: 10.17682/sportjournal/2015.023

Sopa, I.S., and Pomohaci, M. (2014). Group Cohesion Important Factor in Sport Performance. European Scientific Journal,, 10:26, 163-174. doi: http://dx.doi.org/10.19044/esj.2014.v10n26p\%25p

Spink, K.S. (1992). Group Cohesion and Starting Status in Successful and Less Successful Elite Volleyball Teams. Journal of Sports Sciences, 10, 379-388. doi:10.1080/02640419208729934

Taghizadeh, F., and Shojaie, M. (2012). Comparing Emotional Intelligence and Team Cohesion of Elite and Amateur Table Tennis Players. Advances in Applied Science Research, 3:6, 3633-3639

Vallerand, R.J. (1994), Les fondaments de la psychologie sociale, Montreal, Paris: Gaëtan Morin.

Vincer, D.J.E., \& Loughead, T.M. (2010). The Relationship among Athlete Leadership Behaviors and Cohesion in Team Sports. Sport Psychologist, 24, 448-460. 
Widmeyer, W.N., Brawley, L.R., \& Carron, A.V. (1990). The Effects of Group Size in Sport. Journal of Sport and Exercise Psychology, 12, 177-190.

Widmeyer, W.N., \& Williams, J.M.(1991). Predicting Cohesion in a Coacting Sport. Small Group Research, 22, 548-570, Sage Publication. doi: 10.1177/1046496491224007

Williams, J.M., \& Hacker, C.M. (1982). Casual Relationships among Cohesion, Satisfaction and Performance in Women's Intercollegiate Field Hockey Teams. Journal of Sport Psychology, 4, 324-337.

\section{AUTHOR'S ADDRESS:}

Oana Rusu

Faculty of Physical Education and Sport

"Alexandru Ioan Cuza" University of Iasi

Str. Toma Cozma, no. 3, cod

700554, Romania

E-mail: broana@uaic.ro

Received: 27 October 2018; Accepted: 24 May 2019 